\title{
Autonomous Interaction Model in Ubiquitous Learning Systems
}

\author{
Abhinav Garg, \\ M.Tech. (IIIT Bangalore) \\ Assistant Professor \\ National Institute of Fashion Technology \\ Hyderabad, India
}

\author{
Sonam Goel, \\ M.S. (Software Sys.) BITS Pilani \\ Hyderabad, India
}

\begin{abstract}
ICT based learning has become the talk of the time, but they somehow restrain user to think independently. This dependent learning environment should be wisely transformed into selfcreated, self-organized and self-governed. A vibrant presence of independent think tanks would be a hall mark of learning environments. Ubiquitous or always on learning systems provide the users with an opportunity to learn anytime and anywhere. However a forward looking autonomous mechanism with an active feedback system will create true personalization of learning experience. This paper explores various interactions involved in learning and it aims to design a holistic interaction model governed by context aware, adaptive and intelligent systems for Autonomous Ubiquitous Learning.
\end{abstract}

\section{General Terms}

Ubiquitous Learning (u-Learning), Ubiquitous learning systems/devices (ULS), Autonomous Ubiquitous Learning (AUL), Pervasive Learning, Mobile Learning, E-Learning.

\section{INTRODUCTION}

From the inception of computer based learning techniques to omnipresent ubiquitous learning environments, learning methodologies have seen a remarkable paradigm shift. Earlier, class room based teaching and learning was confined to students interacting with teachers and vice versa. Learners were totally dependent on their trainers and the knowledge was confined within the scope of their trainer's intellect. With the advent of e-learning or computer based learning, students were able to shell out of their class rooms and communicate directly with their instructor and peers, using the chat messaging and discussion forums. It gave them an opportunity to work collaboratively in virtual teams using online resources. Then came the era of mobile learning where users carry portable learning devices like cellular phones and PDA's which connect to internet over wireless communication technologies. It enables the users to learn anytime and anywhere by providing them access to shared resources, independently from their physical location i.e. they are free to move while learning. However Pervasive learning uses information about the context of learning from the learning environment where small devices such as sensors, pads and badges are embedded and communicate mutually. It requires heavy setup, thus they offer very low mobility[1].

Traditional class room type and e- learning approaches to learning, typically require a human supervisor to design the learning architecture and protocols, select the training examples, choose the learning algorithm, set the learning parameters, decide when to stop learning, and choose the way in which the performance of the learning algorithm is evaluated[2]. This strong dependence on human supervision retards the self-development of the individual and in turn restricts learning. A forward looking mechanism has to be introduced and practiced, to overcome this limitation. Ubiquitous learning can enhance autonomous learning away from educational establishment in present completely teacherled classrooms. A ubiquitous learning environment is any setting in which students can become totally immersed in the learning process i.e. education is happening all around them but they may not even be conscious of the learning process [3]. Ubiquitous learning has been able to integrate high mobility with highly embedded pervasive learning environments through computer and wireless communications.

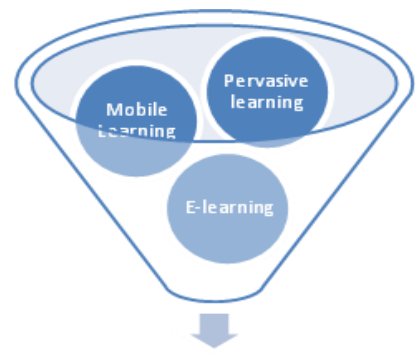

Ubiquitous Learning

Fig 1: Ubiquitous Learning.

Moreover, Autonomous ubiquitous learning enables the learner to learn autonomously, generate their own supervision, select the most informative training samples, produce their own loss function, and evaluate their own performance in an ever changing and uncertain world [4].

Principles of Autonomous learning [5]:

- Develop self-concept and positive self esteem

- Comprehend one's abilities

- Increase knowledge and confidence

- Develop critical and creative thinking skills

- Develop decision-making and problem solving skills 
- Demonstrate responsibility for self-learning

- Become responsible, independent, life-long learners

\section{HISTORY OF AUTONOMOUS LEARNING}

Autonomy often is associated with independence of thought, individualized decision making, and critical intelligence. According to Gibbs (1979)[6], this concept is probably the most familiar, for it is part of an individualistic, antiauthoritarian ideology deep-rooted in Western capitalistic democracies (p. 121). Chene (1983)[7], another Canadian researcher, suggests that autonomy stands for psychological and methodological learning dimensions. Boud (1988)[8] provides several ideas on developing student autonomy. Candy (1991)[9], an Australian adult educator, suggests that continuous learning is a process in which adults manifest personality attributes of personal autonomy in self-managing learning efforts. He also profiles various autonomous learner characteristics

In 1981 George Betts and Jolene Kercher came up with an ALM (Autonomous Learning Model) for meeting the diversified needs of gifted and talented people. They identified 5 dimensions (Orientation, Individual Development, Enrichment, Seminars and In Depth study) which are crucial for the development of autonomous learner.

\section{OBJECTIVE OF THE PAPER}

1. To provide a comprehensive view of learning technologies and discuss possible interactions amongst different actors and systems within the learning model.

2. To provide an autonomous interaction model to create The appropriate blend of all the learning types by Ensuring that each ingredient, individually and Collectively, adds to a meaningful learning Experience.

3. To integrate a variety of current approaches to learning and learning technologies, and will try to establish learning related interactions between distributed actors and resources that are not possible today .

4. To introduce a learning model that is self-organized and will give rise to effective lifelong learning.

\section{GETTING STARTED WITH INTERACTIONS}

Interaction is a kind of action that occurs between two or more objects. Interaction in a traditional classroom is very different from the interaction that occurs in online courses. And that of online courses differs from mobile, pervasive and ubiquitous learning.

\subsection{Classroom Teaching Interaction Model}

Conventional Class room learning is monopolized by teacher and students communicating with each other orally or via boards.

Types of Interaction:

- (Instructor-> Learner) [I2L]: Instructor teaches them course contents, provide them with questionnaires and give them necessary feedback.

- (Learner-> Instructor) [L2I]: Students in turn ask queries, answer questionnaires and listen to what is being taught by teacher.
This kind of face to face communication provides a very little room for independent and lateral thinking. Students just mug up what is being taught, pour it on examination sheets and then they forget it mostly.

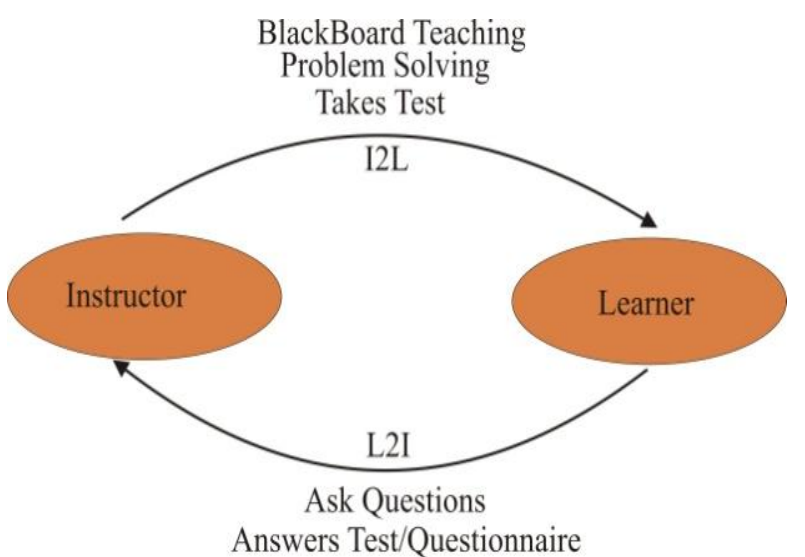

Fig. 2: Classroom Teaching Interaction Model

\subsection{Basic E-Learning or Mobile Learning Interaction Model}

E-learning or Web-based learning or conventional mobile learning has changed the nature of learning from a passive, synchronous delivery system to an engaging, asynchronous arena for the active exchange of ideas. It simply imitates physical classroom-based instructional content over the Internet. Students take lesson in a lively, vivid, and new learning environment and are expected to enhance their learning performance without any burden like attending classes physically. Moreover students get more flexible scope of learning during their convenient time.

Types of Interaction:

- (Instructor to Learner) [I2L]: Instructor teaches them course contents, provide them with questionnaires and give them necessary feedback through computer or mobile supported Elearning devices.

- (Learner to Instructor )[L2I]: Students in turn ask queries answer questionnaires and learn from the contents uploaded by teacher on computer or mobile supported E-learning devices.

- (Learner to Learning device) [L2D]: Learner view lectures, other learning material and submit assignment and answers.

- (Learning device to learner)[D2L]: Learns about learners mental abilities and aptitude.

- (Instructor to Learning device) [I2D]: Instructor uploads lectures, tests, lesson plans, questionnaire, and gives feedback and suggestions.

- (Learning device to Instructor)[D2I]: Helps in framing student centric content and Questions. 


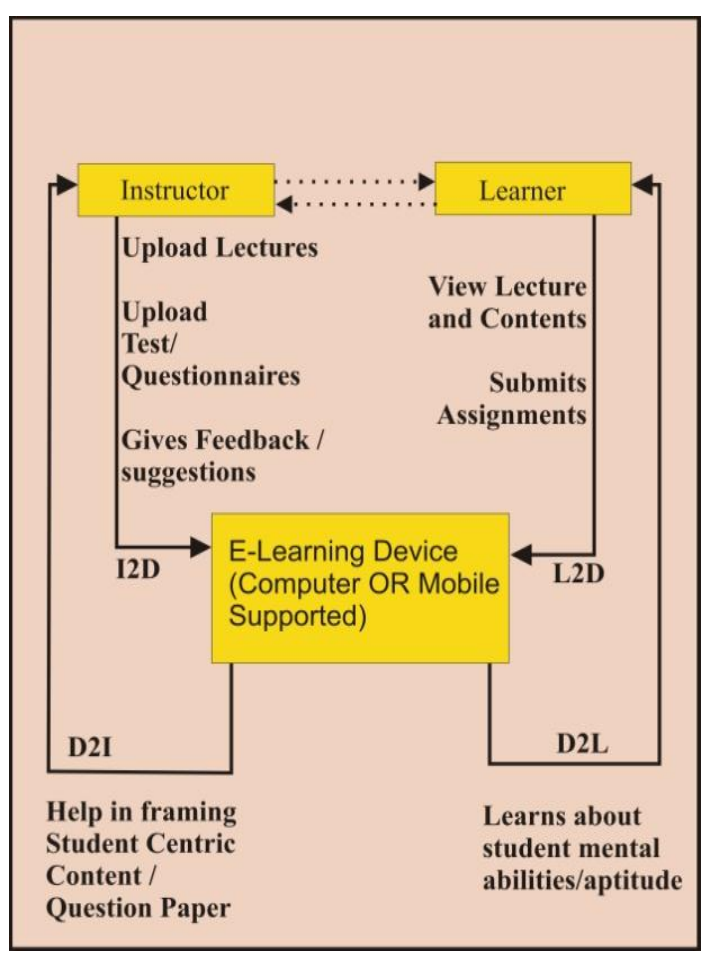

Fig 3: Mobile Learning Interaction Model

- (Pervasive Learning device to Environment or conext) [D2C]: Aware of context sensitive environment.

- (Pervasive Learning device $<->$ Other ICT devices)[D2D]:Learning device retrieves information and user

\subsection{Context Aware Pervasive Learning Interaction Model}

Pervasive learning, uses information about the context of learning from the learning environment. Everyday objects are embedded with sensors, actuators, displays, and computational elements that are able to communicate with one another via wired and wireless networks. It requires heavy setup, thus they offer very low mobility [1]. Emerging technologies such as gaze tracking, speech recognition, gesture recognition, location tracking, and emotion detection combine to create computers that understand and support our interactions with the physical world as well as during our interactions with the virtual world and hence augments learning by opening new arenas of the world to the learner.

Types of Interaction:

- (Learner to Pervasive Learning device)[L2D]: Learner logs in to the device and access environment aware, user aware, and context aware learning material.

- (Pervasive Learning device to learner)[D2L]: Provides updated timely information in user's natural surroundings required data from web and in turn uploads updates onto the web.

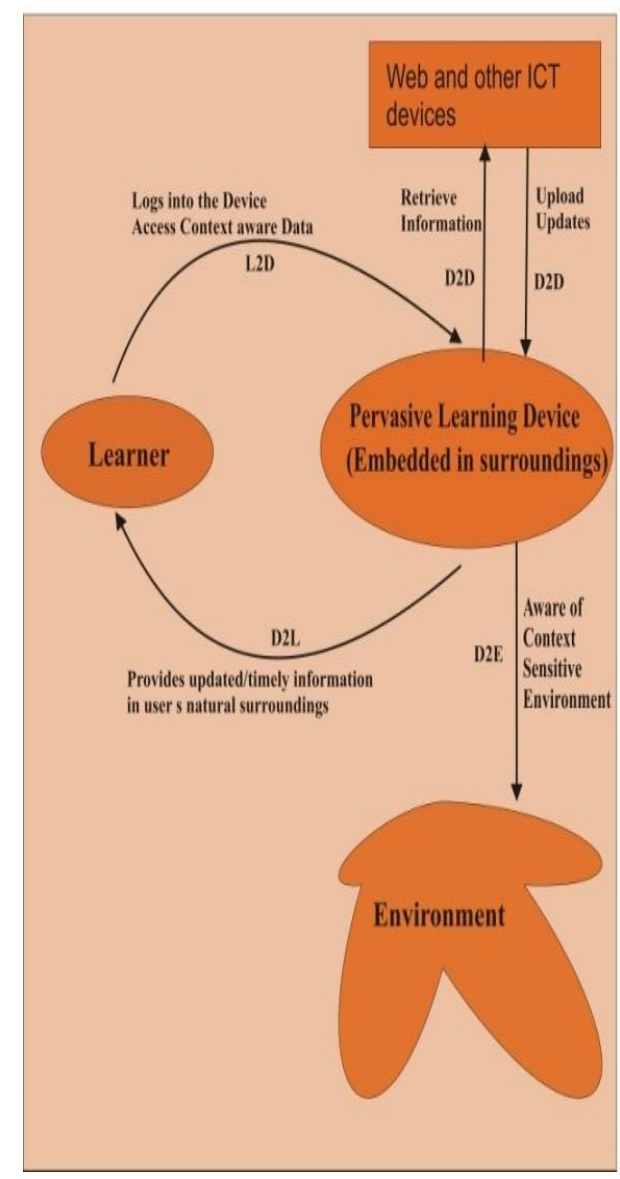

Fig 4: Context Aware Pervasive Learning Interaction Model

\subsection{Prototype of Autonomous Interaction Model for Ubiquitous Learning}

An AUL system can be designed using distributed software services, distributed hardware resources and dynamic cooperation between multiple entities to achieve learner's goal effectively. It can operate autonomously without human intervention and can handle multiple dynamic interactions governed by intelligent systems. AUL systems may include several forms of learning tools, such as real-time virtual collaboration software, self-paced Web-based courses, electronic performance support systems (EPSS) embedded within the job-task environment, and knowledge management systems. In addition to conventional interactions, AUL is based upon interactions of AM (Autonomic Manager) with other devices.

AN AM acts independently and proactively making interactions user centered and more satisfying for the learner. In other words, it enables learners to make choices and decisions, exercising their capacity for autonomy. Thereby, encouraging learners to become aware of the different attributes, experience and features of their own learning environment and to think more explicitly about the choices they can make, so that they actively shape their learning context to ensure a positive learning experience. In AUL systems, learning is triggered by the learner, rather than processed by an instructor. This autonomous approach to 
learning does not focus on setting learning which follows some pre-defined rules, it rather focuses on adaptability and emphasizes learner's self-direction, self-organization, and self-control. Consequently, learners are not responsible for adapting themselves to the requirements of the institution or the instructor. They are rather responsible for creating and maintaining their own learning environments, self-adapted to their individual needs.

Types of Interaction:

- (Learner to Ubiquitous Learning device) [L2D]: Learner $\operatorname{logs}$ in to the device and access environment aware, user aware, and context aware learning material.

- (Ubiquitous Learning device to learner) [D2L]: Provides updated, timely information to the learner anytime and anywhere.

- (Ubiquitous Learning device to Autonomic Manager)[D2AM]:submits user preferences and goals to the $\mathrm{AM}$, senses present context and present to the AM.

- (Autonomic Manager to Ubiquitous Learning device)[AM2D]:create and select tailored contents for specific user, reduce information overload and improve the usability of services, design and filter information and services as per user's personal preferences, AM adapts to context changes in dynamic environment and responds to the user with an active feedback keeping learner's goals, guidelines, past and previous context in mind, AM can make inferences about strengths and weaknesses of learner, and can suggest additional work

- (Ubiquitous Learning device to Environment or context) [D2C]: Aware of context (location, time and user) sensitive environment.

- (Ubiquitous Learning device to Other ICT Devices) [D2D]: Learning device retrieves information and user required data from web and in turn uploads updates onto the web.

\section{Example Scenario:}

Autonomous learning can be of great help to those who are not able to access schools or learning institution like housewives, and for higher studies also. Let us take an example of a student who visits some garden and now wants to study the plants over there. The student logs on to her ubiquitous learning device and opens web browser. The device senses the environment of the student (her location, her emotions, types of plants in front of her, weather and other contexts) and sends them to AM. User submits her goals and preferences. AM analyze and synthesize all the contexts, goals, inputs from other ICT devices and guidelines of the user and present him an appropriate set of lesson plan. User can now create, modify and share her own learning activities with her peers and institutions. In this type of learning scenario learner acts at center stage of the learning process.

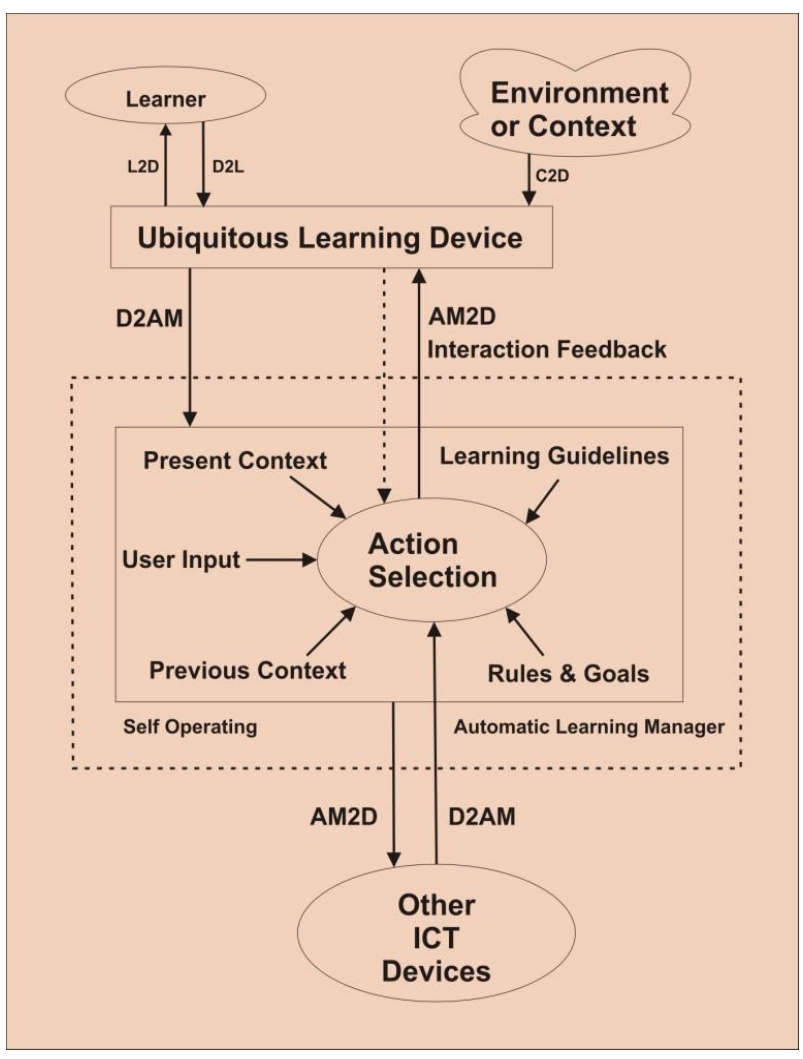

Fig 5: Prototype of Autonomous Interaction Model For Ubiquitous Learning

\section{CONCLUSION AND RECOMMENDATIONS}

In these information rich times, students need to deal with a vast range of information that relates to the rapidly changing nature of the educational environment. Such is the rapid pace of change that the education students receive in school is no longer adequate for them in their work and everyday lives. Only by developing their capacity to become life-long learners who are constantly developing and improving themselves, can people adapt themselves to the increasing challenges of modern society.

Self-motivated and Self-Directed Learning is the key for implementing mechanisms to foster and increase activities in informal and lifelong learning networks. In this paper we have studied various types of interactions that are prevalent in learning systems and proposed the need of an Autonomic manager which takes the responsibility of instructor and organizations. AM is a goal oriented, self-configuring, selfoptimizing and proactive agent which adapts to context changes in dynamic environment and responds to the user with an active feedback keeping learner's goals, guidelines, past and previous context in mind.

In a fast-changing world the need to equip learners for lifelong learning is of paramount importance, and having learnt how to learn is an excellent investment for the future. Once materials or skills are automated, learners begin to improve on their own through further meaningful practice activities. 
Learners begin to speed up performance, to perceive or create new combinations, and to 'do their own thing'. At this stage learners are autonomous. They have little need of a teacher except perhaps as a supportive or challenging colleague and are ready, or nearly ready, to perform as masters of the skills, or as teachers themselves.

\section{REFERENCES}

[1] Ogata, Hiroaki et al "Context-Aware Support for Computer-Supported Ubiquitous Learning" available at "http://citeseerx.ist.psu.edu/viewdoc/summary?doi=10.1. 1.81.5480" (5-April-2013).

[2] Roy, Asim "Autonomous Machine Learning" available at "http://wpcarey.asu.edu/information-systems/asimroy.cfm" (7-April-2013).

[3] "Ubiquitous learning" available at "http://en.wikipedia.org/wiki/Ubiquitous_learning" (9April-2013).
[4] Betts, G "Autonomous Learner Model Optimizing Ability" available at http://www.learningplace.com.au/deliver/content.asp?pid $=13569$ (9-April-2013).

[5] Gibbs, B "Autonomy and authority in education" available http://onlinelibrary.wiley.com/doi/10.1111/j.14679752.1979.tb00527.x/abstract (4-April-2013).

[6] Chene, A et al. "The concept of autonomy in adult education: A philosophical discussion" available at http://aeq.sagepub.com/content/34/1/38.abstract (7-April2013).

[7] Boud, D "Developing Student Autonomy in Learning" available at "http://www.eric.ed.gov" (1-April-2013).

[8] Candy, P C "Self-direction for Lifelong Learning" available

at "http://www.lindenwood.edu/education/andragogy/andra gogy/2011/Candy_1991.pdf”' (2-April-2013). 